\title{
Research Progress on the Antineoplastic Pharmacological Effects and Mechanisms of Litchi Seeds
}

\author{
Juyan Zhang, Cui Zhang* \\ Department of Microbiology and Immunology, Guangdong Pharmaceutical University, Guangzhou, China \\ Email: ${ }^{*}$ ccuizhang@126.com
}

Received 23 December 2014; accepted 13 February 2015; published 16 February 2015

Copyright (C) 2015 by authors and Scientific Research Publishing Inc.

This work is licensed under the Creative Commons Attribution International License (CC BY). http://creativecommons.org/licenses/by/4.0/

(c) (i) Open Access

\begin{abstract}
Researchers have proven the Litchi seeds of possessing salutary pharmacodynamic effects, such as dispelling cold, relieving pain, promoting the circulation of qi, and removing stasis. This has resulted in its categorization as an affinal drug and diet in the traditional Chinese medicine. Important research progress has been obtained on the chemical components, traditional pharmacological effects, antivirus and antitumor effects, their molecular mechanisms and immune effects of litchi seeds in recent years. In this review, we have focused on the antitumor-related effects and mechanisms for the purpose of better utilization and comprehensive understanding of litchi seeds.
\end{abstract}

Keywords

Litchi Seeds, Pharmacological Actions, Molecular Mechanisms, Immune Regulation

\section{Introduction}

Litchi seeds are the drying mature seeds of Sapindaceae litchi family, which shape like globose or oblong eggs and have a smooth and glossy surface in colors of brown or reddish brown. It has demonstrated the pharmacological effects of regulating Qi, dispelling cold and releasing pain. Consequently, it has been used to treat epigastric pain, liver and Qi stagnation, hernia pain, qi-stagnancy and blood stasis of women, testicular swelling, etc. [1]-[3]. The chemical components comprise volatile categories, organic acids and fatty acids, amino acids, saponins, flavonoids, and sugar, and they function significantly on antineoplastic. With intensive research on the chemistry and pharmacology of litchi seeds, some new components and functions have been revealed. It has

\footnotetext{
*Corresponding author.
} 
been now confirmed that the effective ingredients of litchi seeds can be applied to the modulation of blood glucose and blood lipid, anti-oxidation, anti-virus, anti-tumor, and anti-liver injury. In particular, the antitumor effect and the functional mechanisms of litchi seeds in recent years have increasingly attracted numerous attentions of researchers [4]-[6]. To further dig out the precious value of litchi seeds, this work has reviewed recent studies on the pharmacological antitumor effects, the molecular mechanisms and immune effects of litchi seeds.

\section{Pharmacological Antitumor Activity}

The comprehensive progress covering many aspects on the tumor inhibition of litchi seeds has received from the drug serum, extract and relevant active ingredients. Xiao and her coworkers proved that the Litchi medicated serum (water extract and granules) can significantly suppress the cells growth of S180 sarcoma and ehrlich ascites carcinoma (EAC) of mice in vivo and vitro [7], as well as the HepG 2 human liver cancer [8]. Hsu et al. [9] discovered that the polyphenol-rich Litchi seed ethanol extract (LCSP) can significantly induce apoptotic cell death in a dose-dependent manner and arrest cell cycle in G2/M in colorectal carcinoma SW480 and Colo320DM cells. Similar water-soluble crude ethanolic extract in Litchi fruit pericarp also showed a dose- and time-dependent inhibitory effect on the growth of MCF-7 and MDA-MB-231 breast cancer cells where the maximal inhibition of cell growth (>80\%) was obtained at $320 \mu \mathrm{g} / \mathrm{ml}$ with the IC50 $80 \mu \mathrm{g} / \mathrm{ml}$ [10].

In addition, Zhang et al. [11] stated that litchi seeds water extract had a prominent inhibitory effect on the CNE-2Z cell proliferation of nasopharynx cancer. The optimum effect can be obtained after $48 \mathrm{~h}$ experiment, where the inhibition ratio can reach $89.03 \%$ at $50 \mu \mathrm{g} / \mathrm{mL}$ and $98.54 \%$ at $100 \mu \mathrm{g} / \mathrm{mL}$. Zhao et al. [1] investigated the impact of flavonoids and anthocyanins extract in litchi seeds on the breast cancer MCF-7 cell in a methyl thiazolyl tetrazolium (MTT) colorimetric method and found that the half maximal inhibitory concentration (IC50) of Epicatechin and anthocyanin B2 extract are $102 \mu \mathrm{g} / \mathrm{mL}$ and $99 \mu \mathrm{g} / \mathrm{mL}$. In addition, litchi extract shows some degree of antitumor activity on the Liver cancer, cervical cancer and lung cancer [13]-[16]. These works suggested that the chemical components of litchi seeds have a significant tumor inhibition effect and this has been summarized in Table 1.

\section{Molecular-Level Tumor Inhibition Mechanisms}

While the tumor inhibition effects are studied in-depth, the synchronous mechanism explorations make the pharmacodynamic efficacy of litchi seeds more apparent. The apoptosis-inducing is a kind of typical anti-tumor cellular mechanism. It is gradually accepted that the tumor cell proliferation can be inhibited and the tumor cell apoptosis can be induced by regulating the expression of the Bcl-2/Bax protein, the NF- $\kappa \mathrm{b}$ and Fas protein, ultimately inhibiting tumor cell growth.

\subsection{Regulating the Expression of Bcl-2/Bax Protein}

The Bcl-2/Bax protein family plays a vital role in the cells proliferation, which can be classified into two categories, as the channel 1 (CH1) shown in Figure 1. One type belongs to the inhibitor of apoptoasis protein (IAP)

Table 1. Tumor inhibition effect of litchi seeds.

\begin{tabular}{|c|c|c|c|c|c|}
\hline $\begin{array}{l}\text { Active } \\
\text { ingredients }\end{array}$ & Dosage & Cell line & Tumor types & Pharmacological effects & Ref. \\
\hline $\begin{array}{c}\text { Epicatechin } \\
\text { Anthocyanin B2 }\end{array}$ & $\begin{array}{l}102 \mu \mathrm{g} / \mathrm{mL} \\
99 \mu \mathrm{g} / \mathrm{mL}\end{array}$ & MCF-7 & Breast cancer & potential antitumor activity & {$[1]$} \\
\hline \multirow{2}{*}{$\begin{array}{l}\text { Medicated } \\
\text { serum }\end{array}$} & $62 \mathrm{~g} \cdot \mathrm{kg}^{-1} \cdot \mathrm{d}^{-1}$ & $\mathrm{~S} 180$ & Sarcoma, EAC & reduce tumor weight & [7] \\
\hline & $11.80 \mathrm{~g} \cdot \mathrm{kg}^{-1}$ & HepG2 & Liver cancer & inhibit proliferation & [8] \\
\hline Water extract & $\begin{array}{c}50 \mu \mathrm{g} / \mathrm{mL} \\
100 \mu \mathrm{g} / \mathrm{mL}\end{array}$ & CNE-2Z & Nasopharynx cancer & $\begin{array}{l}89.03 \% \text { inhibition ratio } \\
98.54 \% \text { inhibition ratio }\end{array}$ & {$[11]$} \\
\hline Ethanol extract & $>100 \mu \mathrm{g} / \mathrm{mL}$ & $\begin{array}{c}\text { SW480 } \\
\text { Colo320 DM }\end{array}$ & Colorectal carcinoma & $\begin{array}{c}\text { suppress cyclins and elevate the } \\
\text { Bax/Bcl-2 ratio and caspase } 3 \text { activity }\end{array}$ & {$[12]$} \\
\hline Polysaccharide & $\begin{array}{c}50-750 \\
\mu \mathrm{g} / \mathrm{mL}\end{array}$ & $\begin{array}{c}\text { HepG2 } \\
\text { Hela A549 }\end{array}$ & $\begin{array}{c}\text { Liver cancer } \\
\text { Cervical carcinoma } \\
\text { Lung adenocarcinoma }\end{array}$ & Inhibit proliferation & {$[14]$} \\
\hline
\end{tabular}




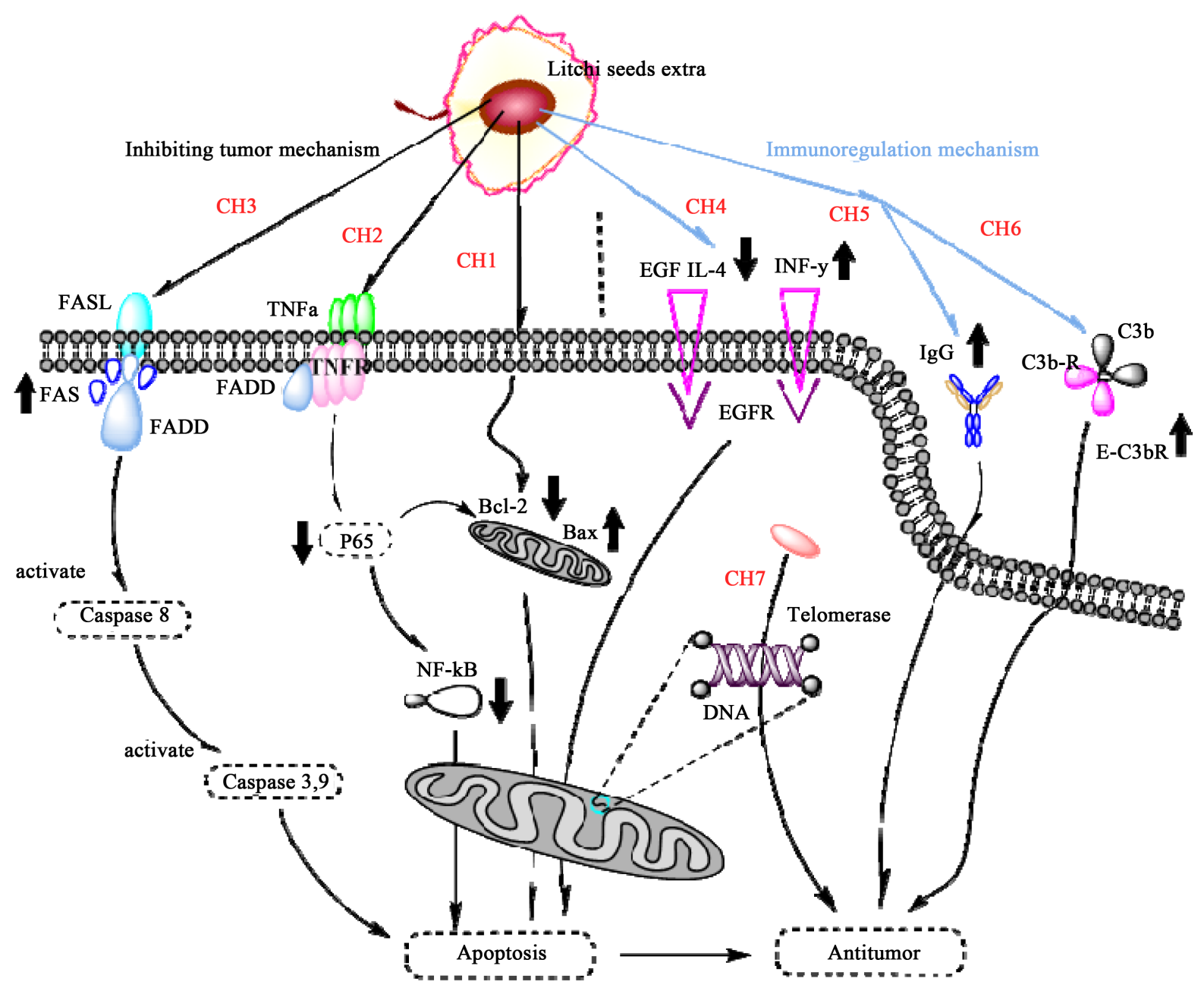

Figure 1. Schematic diagram of proposed antitumor mechanism for litchi seeds.

that mainly contains the Bcl-2, Bcl-XL, Bcl-W, Mcl-1 and CED9, etc. Another is pro-apoptotic protein, including the Bax, Bak, Bcl-XS, Bad, Bik and Bid. Notably, the apoptosis or survival of cells depends on the relative expression level of pro-apoptotic Bax protein and Bcl-2 apoptoasis protein inhibitor to a great extent. Either reducing Bcl-2 protein or increasing the Bax protein can promote apoptosis of tumor cells, otherwise the tumor cell apoptosis will be restrained [17] [18]. Hsu et al. [9] found that Litchi seed ethanol extract (LCSP) can increase the expression of Bax or reduce the expression of Bcl-2 to regulate the apoptosis genes of tumor cells and eventually promote the cell apoptosis.

\subsection{Modulating the Expression of NF- $\kappa \mathrm{B}$}

NF- $\kappa \mathrm{B}$, discovered in B cell since 1986, is one of nucleoproteins anchoring on the light chain enhancer of $\kappa$ immunoglobulin. It has been sorted into five sigmasubunits-Rel (cRel), p65 (RelA, NF- $\kappa$ B3), RelB and p50 (NF- $\kappa \mathrm{B} 1$ ), p52 (NF- $\kappa \mathrm{B} 2$ )-that mainly drive the related gene transcription to realize an antitumor effect [19]. Since NF- $\kappa$ B is a signaling molecule of cell survival in the anti-tumor effect of litchi seeds, inhibiting the expression of NF- $\kappa$ B leads to reducing the expression of p65 subunit and the decrease of antiapoptotic members in the Bcl-2 family, thus eventually inducing the tumor cells apoptosis [20]. Yang et al. analyzed RAW264.7 cells by Western blotting method and found that the alcohol extract of litchi can prevent myocardial infarction via suppressing the activity of NF- $\kappa \mathrm{B}$ [21]. However, a low expression of NF- $\kappa \mathrm{B}$ is discovered in the normal cells and it shows a very limited impact on the normal cells function even if the inhibition works. Therefore, suppressing the NF- $\kappa \mathrm{B}$ and main impact factors in the signal pathway are likely to be the new sensitivity-enhanced 
targets of litchi extract antitumor in future [22]. This part can be seen in CH2.

\subsection{Regulating the Expression of Fas Protein}

Fas protein shows an important effect on the cells apoptosis, which can work as one kind of death receptors combined with the extracellular apoptosis stimulating signal molecules. The extracellular death domain reacts with the FADD to form the death induced signal complex, and then activates the caspase- 8 as well as the following cascade reaction, thus inducing the apoptosis of cells in presence of Fas protein [23]. Wang et al. [24] discussed the HepG-2 proliferation inhibition of Litchi seeds extract and found that the extract L2.3 could stimulate the activity of caspase-8, caspase-3 and caspase- 9 and induce the expression of Fas protein (CH3, Figure 1). Shen et al. discussed the cell proliferation inhibition and apoptosis mechanism of litchi seeds extract for the human neuroblastoma SH-SY5Y cells by a flow cytometry instrument test and revealed that litchi seeds extract can increase the Fas protein to further activate the caspase cascade, and finally induced the apoptosis of SHSY5Y cells [25].

\section{Antineoplastic Immune Regulation Mechanisms}

Litchi seeds extract can regulate the immune molecules and improve the pathological process of various diseases. For example, Litchi seed extract can regulate the cytokines, e.g. epidermal growth factor (EGF), epidermal growth factor receptor (EGFR), platelet derived growth factor (PDGF) and tumor necrosis factor- $\alpha$ (TNF- $\alpha$ ), etc. The litchi polysaccharide can promote the expression of MIF and then control the inflammatory factors like IL-1, TNF- $\alpha$, IFN- $\gamma$. Furthermore, the active ingredients of litchi seeds can stimulate the expression of Ig, C3bR and improve the telomerase activity to release antineoplastic effect.

\subsection{Regulation on the Cytokines}

Epidermal growth factor (EGF) can stimulate certain cell division and proliferation, which is deemed as an important biological mechanism leading to nonmalignant proliferative diseases. Research has shown that EGF can facilitate the DNA synthesis of myoma cells and increase markedly the cell proliferation activity, where the biological effect is linked to the EGFR level of growth factor. Moreover, the high EGFR levels related to excessive myoma cells proliferation show the important role in the growth and development of hysteromyoma [26]. Li et al. [27] discovered the concentrated alcohol extract of Julisanjie bolus, water/alcohol extract and its precipitation, as well as volatile oils reduce significantly both the EGF secretion and the average optical density (MOD) of EGFR-positive expression cells, compared to the positive mifepristone (RU486). In this case, the synergy of active components may be the mainly treatment mechanism of Julisanjie bolus on the uterine fibroids. In addition, litchi polysaccharide LCP50 and LCP50W have proven able to regulate the immune function of mice, in which they can significantly increase the IFN- $\gamma$ secretion of Th1 cells and reduce the IL-4 secretion of Th2 cells (CH4, Figure 1). Thus it can be construed that litchi polysaccharide can regulate the cell factor IFN- $\gamma$ and IL-4 to cure neoplastic disease [28].

\section{2. Regulating the Immunoglobulin (Ig)}

Litchi polysaccharide can also induce the increase of immunoglobulin in serum, as $\mathrm{Li}$ et al. discovered in the immune effect of polysaccharide on mice [29]. Chen et al. [30] further studied the function of litchi seeds on the mice tumor models and its immune adjustment. The agar diffusion method showed that litchi granules increased the IgG of S180 tumor-bearing mice as well as improved their immunocompetence, as displayed in CH5 of Figure 1. This anti-tumor pharmacological function was considered to be the modulation of IgG immune antibody levels and it indicated that litchi seeds accessed the immune response in mice through a humoral immune regulation mechanism.

\subsection{Regulating the Complement Molecules}

Generally, complement receptors are membrane proteins expressed on the surface of immune cells. They interact specifically with complement factors leading to the removal of antigen from the circulation, which is deemed as an important segment in the activation of a mediated complement system. Notably, the C3b receptors 
on erythrocytes can be anchored directly on the C3b-sensitized yeast polysaccharide with the erythrocyte-C3b receptor rosette formed. This plays an important role in the immune adherence and its activity shows a positive correlation to the strength of the immune adhesion [31]-[33]. The immune regulation results of litchi seeds from Chen et al. presented an improvement of E-C3bR in S180 tumor-bearing mice (CH6, Figure 1). The anti-tumor effect on S180 tumor-bearing mice of litchi seeds may be attributed to regulating the activity of C3b complement and C3bR complement receptor [30]. Lin et al. detected the immune adhesion function of red blood cells in a yeast wreath way and revealed that Litchi extract is an efficient inhibitor of hepatitis b surface antigen (HBsAg) [34]. Zhang et al. found that the immune suppression model has lower quantity and activity of C3bR on erythrocytes, compared to that of normal mice, indicating that inhibiting the body immunity can lead to a downswing of E-C3bR formation [35].

\subsection{Regulating the Activity of Telomerase}

Telomere is at the end of the chromosome in eukaryotic cells and chromosomes. The dividing cells are able to synthesize the telomere with telomerase, thus supplementing the loss of telomere in the cell division [36]. The data shows that the normal somatic cells have no telomerase activity, while the immortalized cell family and over $85 \%$ of tumor cells display the telomerase activity. Among of them, $85 \%$ of tumor cells are positively correlated with the activity of telomerase. As a result, considering the telomerase activity as tumor, therapeutic targets has attracted numerous attentions in contemporary medicine science [37] [38]. Xiao et al. [39] imported the different doses of litchi water extract to investigate the anti-hepatoma effects and results showed that litchi water extract reduces significantly the ratio of liver tumor with a negative telomerase activity simultaneously. Therefore, it is proposed that the litchi water extract may inhibit the telomerase activity of liver cancer tissue to suppress the liver cancer, which has been presented in Figure 1, CH7.

\section{The Prospects and Discussion}

As an important ingredient of Chinese traditional medicine, litchi seeds have drawn much attention from its antitumor effect. Litchi seeds can inhibit the tumor cell proliferation, promote tumor cell apoptosis, and restrain the tumor metastasis or work by other means to achieve an anti-tumor effect. This shows that litchi seeds are benign antitumor complementary medicine with various pharmacological functions. In summary, litchi seeds have a positive anti-cancer effect through a variety of molecular mechanisms and immune regulation mechanisms with no serious side effects. Therefore, combining Litchi seeds medicine with radiotherapy and chemotherapy could be a great application and research prospect on enhancing tumor treatment as well as improving the quality of life of cancer patients.

\section{Acknowledgements}

This work was supported by Science and Technology Planning Project of Qianjiang District, China (Nos. 2013099).

\section{References}

[1] Castellain, R.C., Gesser, M. and Tonini, F. (2014) Chemical Composition, Antioxidant and Antinociceptive Properties of Litchi chinensis Leaves. Journal of Pharmacy and Pharmacology, 6, 1796-1807. http://dx.doi.org/10.1111/jphp.12309

[2] Hwang, J.-Y., Lin, J.-T. and Liu, S.-C. (2013) Protective Role of Litchi (Litchi chinensis Sonn.) Flower Extract against Cadmium- and Lead-Induced Cytotoxicity and Transforming Growth Factor $\beta 1$-Stimulated Expression of Smooth Muscle-Actin Estimated with Rat Liver Cell Lines. Journal of Functional Foods, 5, 698-705. http://dx.doi.org/10.1016/j.jff.2013.01.013

[3] Jiang, G., Lin, S. and Wen, L. (2013) Identification of Anovel Phenolic Compound in Litchi (Litchi chinensis Sonn.) Pericarp and Bioactivity Evaluation. Food Chemistry, 136, 563-568. http://dx.doi.org/10.1016/j.foodchem.2012.08.089

[4] Zhao, M., Yang, B. and Liu, Y. (2007) Immunomodulatory and Anticancer Activities of Flavonoids Extracted from Litchi (Litchi chinensis Sonn.) Pericarp. International Immunopharmacology, 7, 162-166. http://dx.doi.org/10.1016/j.intimp.2006.09.003

[5] Wen, L., Wu, D. and Jiang, Y. (2014) Identification of Flavonoids in Litchi (Litchi chinensis Sonn.) Leaf and Evaluation of Anticancer Activities. Journal of Functional Foods, 6, 555-563. http://dx.doi.org/10.1016/j.jff.2013.11.022 
[6] Lin, C.C., Chung, Y.C. and Hsu, C.P. (2013) Anti-Cancer Potential of Litchi Seed Extract. World Journal of Experimental Medicine, 3, 56-61.

[7] Lin, N., Xiao, L.Y. and Pan, J.Q. (2008) Effects of Semen Litchi on the Expressions of S180 and EAC Tumor Cells and Bax and Bcl-2 Proteins in Rats. China Pharmacy, 19, 1138-1140.

[8] Xiong, A.H., Shen, W.J. and Xiao, L.Y. (2008) Effect of Semen Litchi Containing Serum on Proliferation and Apoptosis of HepG2 Cells. Journal of Chinese Medicinal Materials, 31, 1533-1536.

[9] Hsu, C.P., Lin, C.C. and Huang, C.C. (2012) Induction of Apoptosis and Cell Cycle Arrest in Human Colorectal Carcinoma by Litchi Seed Extract. Journal of Biomedicine and Biotechnology, 2012, Article ID: 341479. http://dx.doi.org/10.1155/2012/341479

[10] Wang, X., Yuan, S. and Wang, J. (2006) Anticancer Activity of Litchi Fruit Pericarp Extract against Human Breast Cancer in Vitro and in Vivo. Toxicology and Applied Pharmacology, 215, 168-178. http://dx.doi.org/10.1016/j.taap.2006.02.004

[11] Zhang, N., Zhou, Z. and Feng, X. (2012) Comparison and Elevation on Antitumor Activity in Vitro of the Litchi Seeds and Longan Seeds Water Extract. Hunan Journal of Traditional Chinese Medicine, 28, 133-135.

[12] Wang, X., Xiao, L. and Pan, J. (2007) Experimental Studies of Effects of Antitumor of Litchi Seed Ke Li and the Activity of in the Tissue-End of EAC, S180 and Hepatic Carcinoma of Rats. China Healthcare Innovation, 2, 54-56.

[13] Lv, Q., Si, M. and Yan, Y. (2014) Effects of Phenolic-Rich Litchi (Litchi chinensis Sonn.) Pulp Extracts on Glucose Consumption in Human HepG2 Cells. Journal of Functional Foods, 7, 621-629. http://dx.doi.org/10.1016/j.jff.2013.12.023

[14] Huang, F., Zhang, R. and Yang, Y. (2014) Comparison of Physicochemical Properties and Immunomodulatory Activity of Polysaccharides from Fresh and Dried Litchi Pulp. Molecules, 19, 3909-3925. http://dx.doi.org/10.3390/molecules19043909

[15] Wen, L., He, J. and Wu, D. (2014) Identification of Sesquilignans in Litchi (Litchi chinensis Sonn.) Leaf and Their Anticancer Activities. Journal of Functional Foods, 8, 26-34. http://dx.doi.org/10.1016/j.jff.2014.02.017

[16] Xu, X., Xie, H. and Hao, J. (2010) Eudesmane Sesquiterpene Glucosides from Lychee Seed and Their Cytotoxic Activity. Food Chemistry, 123, 1123-1126. http://dx.doi.org/10.1016/j.foodchem.2010.05.073

[17] Al-Fatlawi, A.A., Al-Fatlawi, A.A. and Irshad, M. (2014) Rice Bran Phytic Acid Induced Apoptosis through Regulation of Bcl-2/Bax and p53 Genes in HepG2 Human Hepatocellular Carcinoma Cells. Asian Pacific Journal of Cancer Prevention, 15, 3731-3736. http://dx.doi.org/10.7314/APJCP.2014.15.8.3731

[18] Guo, L., Xiao, S. and Guo, Y. (2004) Detection of Bcl-2 and Bax Expression and bc-2/JH Fusion Gene in Intrahepatic Cholangiocarcinoma. World Journal of Gastroenterology, 10, 3251-3254.

[19] Pamukcu, B., Lip, G.Y.H. and Shantsila, E. (2011) The Nuclear Factor-kappaB Pathway in Atherosclerosis: A Potential Therapeutic Target for Atherothrombotic Vascular Disease. Thrombosis Research, 128, 117-123. http://dx.doi.org/10.1016/j.thromres.2011.03.025

[20] Chen, L., Zhang, X. and Chen, J. (2014) NF- $\kappa$ B Plays a Key Role in Microcystin-RR-Induced HeLa Cell Proliferation and Apoptosis. Toxicon, 87, 120-130. http://dx.doi.org/10.1016/j.toxicon.2014.06.002

[21] Yang, D.J., Chang, Y.-Y. and Lin, H.W. (2014) Inhibitory Effect of Litchi (Litchi chinensis Sonn.) Flower on Lipopolysaccharide-Induced Expression of Proinflammatory Mediators in RAW264.7 Cells through NF- $\kappa$ B, ERK, and JAK2/ STAT3 Inactivation. Journal of Agricultural and Food Chemistry, 62, 3458-3465. http://dx.doi.org/10.1021/jf5003705

[22] Olajide, O.A., Heiss, E.H. and Wright, C.W. (2007) Synthetic Cryptolepine Inhibits DNA Binding of NF-kappaB. Bioorganic \& Medicinal Chemistry, 15, 43-49. http://dx.doi.org/10.1016/j.bmc.2006.10.018

[23] Liang, Z., Guo, Y.T. and Y,i Y.J. (2014) Ganoderma Lucidum Polysaccharides Target a Fas/Caspase Dependent Pathway to Induce Apoptosis in Human Colon Cancer Cells. Asian Pacific Journal of Cancer Prevention, 15, 3981-3986. http://dx.doi.org/10.7314/APJCP.2014.15.9.3981

[24] Wang, H., Shen, W. and Huang, X. (2010) Antiprolifeative and Induced Apptosis Effects of Litchi Seeds Extract on HepG-2 Cells. Journal of Jinan University (Natural Science \& Medicine Edition), 31, 364-368.

[25] Shen, W., Wen, X. and Wang, H. (2010) Growth Inhibitory and Apoptosis-Inducing Effects of Litchi Seed Extract on Human Neuroblastoma SH-SY5Y Cells. Pharmacology and Clinics of Chinese Materia Medica, 26, 45-48.

[26] Li, W., Lin, Q. and Lin, J. (2002) Study on Relationship between Cell Proliferation of Uterus Leiomyoma and Epidermal Growth Factor-Receptor. Shanghai Medical Journal, 25, 202-204.

[27] Li, K., Guan, Y. and Li, Y. (2011) Influences of Effective Fractions of Ju Li San Jie Wan on Expression of EGF, EGFR and PR-A in Uterine Leiomyoma Cells. Journal of Beijing University of Traditional Chinese Medicine, 34, 455459.

[28] Jing, Y., Huang, L. and Lv, W. (2014) Structural Characterization of a Novel Polysaccharide from Pulp Tissues of Lit- 
chi chinensis and Its Immunomodulatory Activity. Journal of Agricultural and Food Chemistry, 62, 902-911. http://dx.doi.org/10.1021/jf404752c

[29] Li, X.-H., Li, F.-S. and Wei, W. (2008) Effect of Litchi Polyacchaarides on Immunological Function of Mice. Lishizhen Medicine and Materia Medica Research, 19, 2119-2120.

[30] Chen, F., Hu, J. and Xiao, L. (2009) Experimental Study of Litchi Seed on Mouse Tumor Animal Model and Immune Regulation. Journal of Chinese Medicinal Materials, 32, 774-776.

[31] Pilzer, D., Gasser, O. and Fishelson, Z. (2005) Emission of Membrane Vesicles: Roles in Complement Resistance, Immunity and Cancer. Springer Seminars in Immunopathology, 27, 375-387. http://dx.doi.org/10.1007/s00281-005-0004-1

[32] Pio, R., Ajona, D. and Lambris, J.D. (2013) Complement Inhibition in Cancer Therapy. Seminars in Immunology, 25, 54-64. http://dx.doi.org/10.1016/j.smim.2013.04.001

[33] Moghimi, S.M. (2014) Cancer Nanomedicine and the Complement System Activation Paradigm: Anaphylaxis and Tumour Growth. Journal of Controlled Release, 190, 556-562. http://dx.doi.org/10.1016/j.jconrel.2014.03.051

[34] Lin, N., Xiao, L.Y. and Zhang, D. (2007) Experimental Studies of Effects of Antitumor of Litchi Seed and Immunology Adhering in Red Cell of Hepatic Carcinoma. China Healthcare Innovation, 2, 1-2.

[35] Pikovski, M.A., Ziffroni-Gallon, Y. and Witz, I.P. (1975) Suppression of Immune Response to Sheep Red Blood Cells in Mice Treated with Preparations of a Tumor Cell Component and in Tumor-Bearing Mice. European Journal of Immunology, 5, 447-450. http://dx.doi.org/10.1002/eji.1830050704

[36] Xu, Q. and Zhu, B. (2012) The Research Progress on Telomere, Telomerase and hTERT/hTERC Genes. Journal of Molecular Diagnostics and Th, 4, 267-271.

[37] Kheirollahi, M., Mehrazin, M. and Kamalian, N. (2013) Telomerase Activity in Human Brain Tumors: Astrocytoma and Meningioma. Cellular and Molecular Neurobiology, 33, 569-574. http://dx.doi.org/10.1007/s10571-013-9923-X

[38] Liu, Z., Zhong, J. and Chai, Z. (2014) The Significance and Progress of Telomere and Telomerase in Cancer. Life Science Research, 18, 261-264.

[39] Xiao, L., Hong, Z. and Jiang, J. (2007) Anti-Tumor Effect of Semen Litchi and Its Effect on Telomerase Activation of Hepatoma Tissue. China Pharmacy, 18, 1366-1367. 
Scientific Research Publishing (SCIRP) is one of the largest Open Access journal publishers. It is currently publishing more than 200 open access, online, peer-reviewed journals covering a wide range of academic disciplines. SCIRP serves the worldwide academic communities and contributes to the progress and application of science with its publication.

Other selected journals from SCIRP are listed as below. Submit your manuscript to us via either submit@scirp.org or Online Submission Portal.
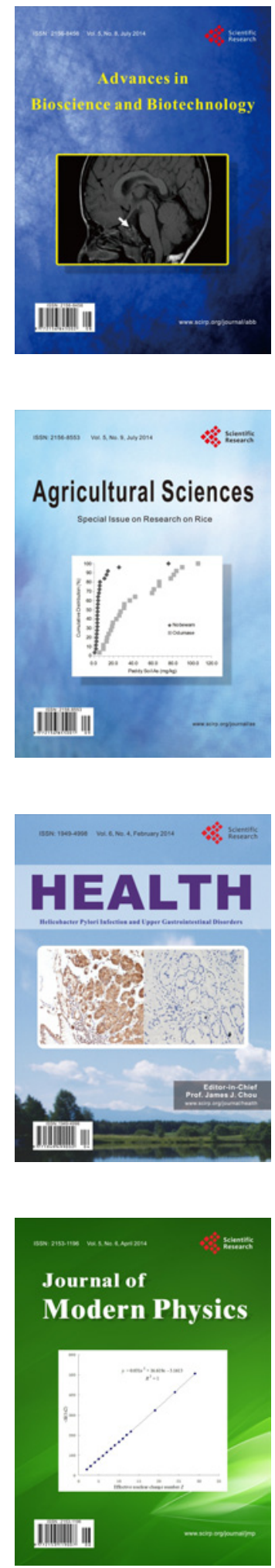
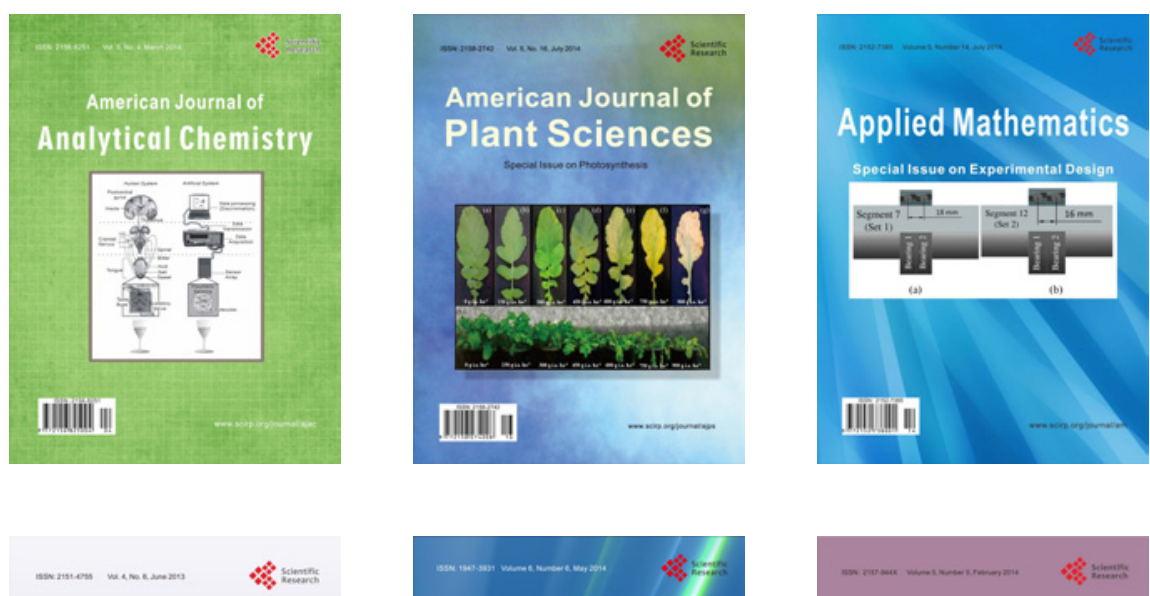

Creative Education
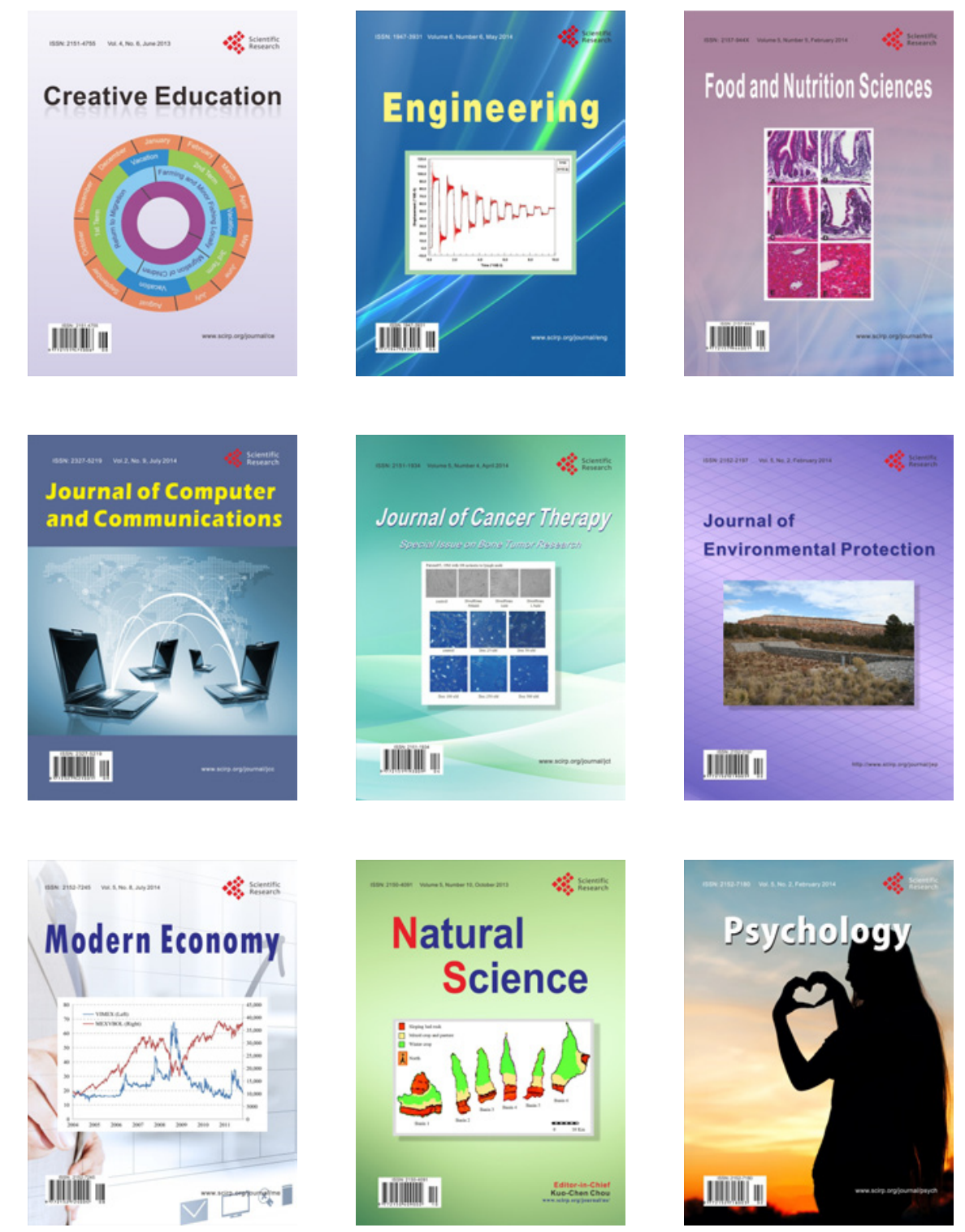